\title{
REPRESENTASI PORNOGRAFI DALAM FILM JAN DARA
}

\author{
Fathul Nia, Redi Panuju \\ Universitas dr Soetomo \\ Jalan Semolowaru 84 Surabaya 60118 \\ Email : redipanuju@gmail.com
}

\begin{abstract}
Film is an audio visual communication media to convey a certain message. So most of the movies show a presence in a drama movie can be seen from how women are positioned and represented. The drama film that was studied and analyzed was a movie titled Jan dara. According to laura mulvey cinematic techniques construct a woman as an object of desire and a view for the people behind the screen as well as the audience by highlighting the representation of the female body shape as the main side of sexuality for the object of visual pleasure. In this case cinematic techniques were analyzed which were used in various angles of camera gaze, lighting. So from the analysis results known that cinematic techniques both shooting and lighting techniques in order to be used to launch the desire to look at men and exploit the body of the woman for visual pleasure.
\end{abstract}

Keywords: film, male gaze, pornography and sexuality, women.

\begin{abstract}
ABSTRAK
Film merupakan media komunikasi yang bersifat audio visual untuk menyampaikan pesan tertentu. Kehadiran perempuan dalam film drama dapat dilihat dari bagaimana perempuan diposisikan dan direpresentasikan. Film drama yang diteliti dan dianalisis yaitu film berjudul Jan Dara. Menurut Laura Mulvey, teknik sinematik mengonstruksi perempuan sebagai objek hasrat dan pandangan bagi orangorang di balik layar maupun penonton dengan menggarisbawahi representasi bentuk tubuh perempuan sebagai sisi utama seksualitas untuk objek kesenangan visual. Dalam hal ini, yang dianalisis adalah teknik sinematik yang digunakan dalam berbagai sudut tatapan kamera atau pencahayaan. Dari hasil analisis diketahui, teknik sinematik baik teknik pengambilan gambar maupun pencahayaan dapat digunakan untuk melancarkan hasrat memandang laki-laki serta mengeksploitasi tubuh perempuan demi kesenangan visual.
\end{abstract}

Kata kunci: film, male gaze, pornografi dan seksualitas, perempuan.

\section{Latar Belakang}

Pada era informasi saat ini,

media massa merupakan hal yang tidak

dapat dipisahkan dari kehidupan

masyrakat. Manusia yang disebut

sebagai makhluk sosial tidak pernah

lepas dari proses interaksi sosial, dan

proses interaksi sosial tidak pernah

lepas dari informasi. Sedangkan informasi diperoleh atau diakses dengan

mudah melalui media massa yang memproduksi dan menyebarluaskan. Informasi tersebut dikemas sedemikian rupa untuk selanjutnya dipulikasikan melalui media cetak, media elektronik dan media online.

Sejarah perkembangan media massa berubah drastis pada sejak 
digulingkannya Orde Baru pada 1998.

Di awal era reformasi, media massa, cetak maupun elektronik memiliki peranan besar dalam proses terjadinya reformasi. Media massa mampu membawa perubahan di bidang politik, pendidikan, komunikasi, dan sebagainya. Media massa diartikan sebagai penyebaran informasi melalui buku, surat kabar, majalah, film, radio, program-program televisi, CD, DVD, dan sebagainya (Straubhaar dan La Rose, 2002). Turow (2009) melihat media massa sebagai instrumen teknologi dari komunikasi massa, yakni "the industrialize production and multiple distribution of messages through technological device." (Dalyono, 2010)

Seiring perkembangan zaman di era gelobalisasi, teknologi digital sangat berkembang pesat. Adanya media massa berupa internet mempermudah orang mengakses apapun dari berbagai belahan dunia, salah satunya film. Film awalnya hanya dianggap media untuk menghibur. Namun sebenarnya film juga merupakan media yang digunakan untuk menyampaikan informasi kepada khalayak luas. Film merupakan media komunikasi audio-visual untuk menyampaikan pesan terhadap kelompok orang. Film memiliki berbagai genre, misalnya aksi, horor, drama dan sebagainya. Salah satu genre yang digemari masyarakat secara umum adalah film drama. Film tidak hanya menyajikan sesuatu yang berupa fiksi dan menghibur saja, namun dalam perkembangannya film dikombinasikan dengan berbagai sisi kehidupan manusia yang berkaitan dengan pendidikan, teknologi dan sebagainya. Hal ini dilakukan agar proses pembelajaran tersampaikan secara implisit sehingga terasa lebih menyenangkan.

Pada pertengahan 1920-an, studio film telah menjadi pabrik 
pengalihan perhatian, melarikan pikiran masyarakat dari masalah sehari-hari dan menjadi obat melawan kebosanan yang di dalamnya tetap mengandung nilainilai moral yang diinginkan (Danesi, 2010). Namun terdapat film yang tidak memiliki pesan moral, contohnya adalah film yang mengandung unsur pornografi. Pornografi bagi sebagian dianggap menjijikkan karena berkaitan dengan adegan seks. Pornografi sebenarnya adalah topik sangat menarik diperbincangkan dalam konteks media massa. Media pun memanfaatkan hal tersebut sebagai komoditas dengan secara sengaja menampilkan unsurunsur pornografi sebagai sarana komersial. Contoh, media massa yang menampilkan film dengan unsur pornografi yaitu film layar lebar Indonesia berjudul Hantu Binal Jembatan Semanggi, dan selain itu terdapat pula film dari Thailand yaitu Jan Dara.
Film dengan unsur pornografi telah banyak beredar di berbagai belahan dunia melalui internet. Namun tidak tersebar secara luas dan tidak dapat ditonton semua kalangan, karena terdapat beberapa negara yang memiliki peraturan tersendiri terkait batasan pornografi. Salah satunya Indonesia yang memiliki peraturan tentang perfilman dan pornografi seperti UU Nomor 33 Tahun 2009 tentang Perfilman dan UU Nomor 44 Tahun 2008 dan KUHP Tahun 2005 tentang Pornografi.

Masuknya budaya Barat yang di blow-up di media massa telah menjadi tren yang membahayakan budaya Indonesia termasuk seks bebas. Tren ini dimanfaatkan industri perfilman untuk mengendalikan perfilman Indonesia sesuai ideologi Barat. Negara yang sudah lama terpengaruh dan lama-kelamaan menjadi libertarian akan dipengaruhi pasar. Film Jan Dara bisa dijadikan 
contoh film yang mengandung unsur pornografi dalam upaya meraih kepuasan.

Film bioskop kini dapat diakses secara mudah melalui internet. Panuju (2017) mengurai dampak penggunaan internet di kalangan anak-anak dan remaja. Panuju menemukan fakta bahwa anak anak dapat mengakses pornografi melalui warung kopi yang tersebar di mana mana.

Jan Dara merupakan film yang mengisahkan seorang anak yang memiliki kekayaan di salah satu wilayah Thailand. Kisah tersebut dimulai ketika sang ibu meninggal sesaat setelah melahirkan Jan. Sejak kecil Jan mendapat siksaan dan ketidakadilan dari ayah tiri karena bukan garis keturunannya. Film tersebut dibagi menjadi dua bagian, yaitu Jan Dara The Beginning dan Jan Dara The Finale. Jan Dara The Beginning mengisahkan tentang ayah tiri Jan yang mengambil alih kekuasaan/kekayaan dari sang pemilik serta masa muda Jan. Sedangkan Jan Dara The Finale mengisahkan tentang kebenaran asalusul dan upaya merebut kembali haknya.

Film tersebut bergenre drama dengan banyak bumbu erotis, bahkan di beberapa scene/adegan diperlihatkan hubungan seksual yang dilakukan Bibi Wad dan Luang Wisnan/ayah tiri Jan tanpa sensor. Film tersebut menunjukkan kondisi psikis tiap tokoh yang mengalami perubahan. Hal tersebut terlihat saat Nona Dara (ibu kandung Jan) yang meninggal sesaat setelah melahirkan Jan, tiba-tiba memusuhi Jan yang masih bayi. Sedangkan ayah tiri Jan tanpa sebab sering memarahi dan bahkan menyiksa Jan secara brutal sampai berdarah hingga pingsan.

Berdasarkan hal tersebut, peneliti ingin menganalisis alur cerita dan 
karakter setiap tokoh. Analisis alur cerita menggunakan analisis naratif Laura Mulvey untuk mengkaji visual pleasure dalam film. Sedangkan untuk karakter tokoh dalam film, peneliti menggunakan kajian psikoanalisis. Penelitian ini ingin mengurai representasi pornografi dalam film Jan Dara dengan Analisis Naratif dan kajian psikoanalisis tentang meraih kepuasan.

\section{Tinjauan Pustaka}

\section{A. Kajian Terdahulu}

Film adalah teks yang memuat serangkaian citra fotografi yang mengakibatkan adanya ilusi gerak dan tindakan dalam kehidupan nyata (Danesi, 2010). Sedangkan dalam pengertian lain, film adalah gambar hidup hasil dari seonggok seluloid yang diputar dengan menggunakan proyektor dan ditembakkan ke layar yang dipertunjukkan di gedung bioskop
(Romli, 2016). Dapat disimpulkan, film adalah teks yang memuat serangkaian gambar hidup menghasilkan ilusi gerak serta tindakan dalam kehidupan nyata dengan menggunakan proyektor dan dipertunjukkan di bioskop.

Di dalam film terdapat beberapa karakteristik/genre yakni genre action/laga, horor, komedi, thriller, ilmiah, atau drama. Berdasarkan karakteristik/genre yang telah dijelaskan di atas, film selalu terkait dengan unsurunsur pembentuk film, sehingga muncul beberapa unsur pembentuk film yakni unsur naratif dan sinematik. Unsur naratif adalah bahan (materi) yang diolah dalam film cerita itu sendiri yang berhubungan dengan aspek cerita/tema film. Setiap film memiliki unsur naratif, seperti alur, tema, setting, dan tokoh. Unsur sinematik adalah cara (gaya) untuk mengolah unsur naratif atau aspek-aspek teknik dalam pembuatan film. Di dalam unsur sinematik terdapat 4 elemen, yakni mise-en-scene, 
sinematografi, editing dan suara (Pratista, 2010).

\section{B. Pornografi dan Konsep Seksualitas}

Pornografi merupakan kejahatan yang memikat, sehingga ia memanfaatkan libido seksual setiap manusia, termasuk remaja dan anakanak. Kelompok usia inilah yang sekarang rentan menjadi korban pornografi; apakah mengkonsumsinya, terdorong melakukan kejahatan seksual atau menjadi korban dan sebagai representasi ekspisit (gambar, lukisan, tulisan) dari aktivitas seksual atau dari hal yang tidak senonoh seperti mesum dan cabul yang dimaksudkan sebagai sesuatu yang disengaja dengan membangkitkan seksualitas (Januar, 2014). Konsep tentang seksual dan perkembangan seksual pertama kalinya diterbitkan oleh Freud dalam Three Essays On Sexuality (1905). Konsep tersebut merupakan hal sangat penting dalam psikoanalisis sejak tahap awal. Freud mengemukakan sulitnya menguraikan secara pasti apa yang dimaksud seksualitas. Terdapat beberapa pandangan yang menjelaskan kata “seksualitas.”

Di pihak lain, pandangan bahwa kata seksual menyangkut kontak kelamin yang berbeda jenis memiliki arti yang sempit. Dengan demikian, kata seksualitas hanya dikaitkan dengan sesuatu yang tidak patut. Lebih lanjut lagi Freud mengemukakan, kata seksualitas berarti segala sesuatu menyangkut reproduksi dan mengabaikan sejumlah kegiatan seperti ciuman dan masturbasi. Freud kemudian menyimpulkan, seksualitas berarti menyangkut semua yang telah disebutkan di atas ditambah sejumlah hal lagi. Terdapat beberapa teori yang dikemukakan Freud, diantaranya tahap oral (0-1 tahun), tahap anal (1-3 tahun), tahap phallic (3-5 tahun), tahap latensi 
(6-12 tahun), kompleks Oedipus, sex appeal (daya tarik sex), sex violence, penyimpangan seksual (meliputi penyimpangan yang menyangkut objek seksual, penyimpangan yang menyangkut tujuan seksual, inversi, fetitisme, memandang dan menyentuh, sadisme dan masokisme).

\section{Analisis Naratif}

Analisis naratif adalah analisis mengenai narasi baik narasi fiksi (novel, puisi, film, komik dan sebaginya), atau fakta (Eriyanto, 2013). Analisis ini tidak hanya menjadi kajian kaku terhadap teks, namun memiliki hubungan sangat erat dengan analisis budaya (cultural analysis) atau yang disebut cultural studies (Lilik, 2015). Namun dalam perkembangannya, analisis naratif terhadap film menimbulkan persoalan representasi dan posisi perempuan dalam media seperti pandangan Laura Mulvey tentang Visual Pleasure and Narative Cinema yang karyanya berfokus pada tiga isu. Pertama, posisi gender seperti, perempuan dilihat dengan cara tertentu dan terlihat dalam posisi pasif. Kedua, dia melihat heteroseksualitas dalam pandangan lakilaki. Mulvey melihat, pandangan lakilaki sebagai sekadar interaksi heteroseksual ketika seseorang menatap perempuan (Rivi, 2017). Sehingga terdapat konsep atau gagasan "male gaze (tatapan laki-laki)” yang mengibaratkan bagaimana seorang lakilaki sedang menatap perempuan, yang seringkali tidak sadar tentang apa yang sedang ia lakukan. Perasaan seksual dan emosionalnya mendahului ketika memandang perempuan. Sehingga, tampilan perempuan di dalam media cenderung tunduk pada kontrol tatapan laki-laki. (Kosut, 2012).

\section{Psikoanalisis}

Psikoanalisis merupakan pandangan baru tentang manusia, di mana ketidaksadaran memainkan peranan sentral. Dalam hal ini Freud mengajukan pandangan mengenai 
konsep psikoanalisis seperti beberapa

pembagian jiwa yang terdiri dari:

- Id; merupakan wilayah gelap, tidak bisa diakses, nafsu-nafsu naluriah dan satu-satunya realitas kebutuhannya sendiri yang egois, bagian di mana ketidaksadaran primitif di dalam pikiran yang lahir bersama kita.

- Ego; merupakan bagian dari pikiran yang bereaksi terhadap kenyataan eksternal, serta dianggap sebagai diri. Dari kata lain “aku”.

- Super-Ego; merupakan anak yang masih kecil, tidak bermoral, hanya memiliki sedikit kepekaan terhadap gangguan dan berkembang setelah kompleks oedipus yang mulai terselesaikan.
Setelah dimulainya represi terhadap dorongan oedipal ini, si anak yang merasakan “gado-gado cinta," takut, dan permusuhan terhadap kedua orangtua.

- Kecemasan; merupakan konflik antara berbagai aspek di dalam kepribadian yang mengakibatkan kecemasan dan setres. Freud mengatakan, kecemasan bertindak sebagai tanda peringatan mengenai sesuatu yang tidak beres dan mengidentifikasi tiga macam kecemasan yakni kecemasan realistic, kecemasan neurotic, kecemasan moral, mekanisme pertahanan (meliputi represi, penolakan, pengalihan, proyeksi, khayalan, rasionalisasi, 
formasi reaksi), transferensi, narcissism, mourning dan melancholia, naluri, eros dan thanatos.

\section{Metode}

Tipe penelitian yang digunakan adalah kualitatif, di mana tipe penelitian ini bersifat deskriptif. Pendekatan kualitatif bertujuan untuk menjelaskan atau menggambarkan suatu masalah yang hasilnya dapat digeneralisasikan sedalam-dalamnya melalui pengumpulan data (Kriyantono, 2012). Ssenada dengan hal tersebut, Taylor dan Bogdan dalam Moleong (2013) mengemukakan, metode kualitatif adalah prosedur penelitian yang menghasilkan data deskriptif berupa kata-kata lisan maupun tertulis dari orang-orang dan perilaku yang dapat diamati.

Dengan demikian penelitian deskriptif-kualitatif merupakan bentuk penelitian yang ditujukan untuk

mendeskripsikan fenomena, baik fenomena alamiah maupun fenomena yang dibuat seseorang. Penelitian deskriptif-kualitatif ini bertujuan untuk menjelaskan data-data secara sistematis, rinci, lengkap dan mendalam serta menjawab masalah yang akan diteliti. Penelitian ini berfokus pada karakter tokoh yang merujuk pada perilaku menyimpang serta mengandung unsur pornografi dalam meraih kepuasan. Dialog yang telah peneliti pilih akan dianalisis menggunakan metode analisis naratif model Himawan, namun dalam pandangan Laura Mulvey.

\section{Temuan Penelitian dan Pembahasan}

\section{A. Representasi Pornografi dalam}

Film Jan Dara The Beginning-The Finale

\section{Tabel 1}

Adegan Film Kategori Deskripsi




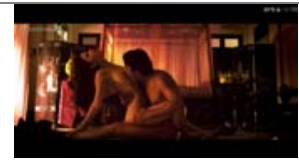

Gambar 1

Ayah tiri Jan dan pembantu

Adegan
menunjuk
kan
kategori
hubungan
intim

Menunjuk

kan

perilaku

kotor

ayah tiri

Jan

setelah

kematian

Nona

Dara atau

istrinya.

Perilaku

tersebut

dilakukan

dengan

tujuan

menakluk

kan para

pembantu

wanita di

rumah

besar agar

tunduk

pada

perintahn

ya

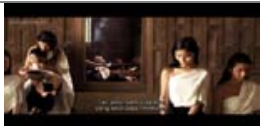

Gambar 2

Ayah tiri Jan dan pembantu

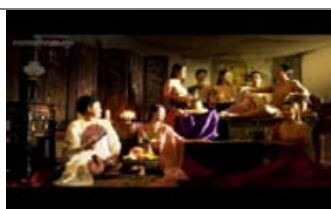

Gambar 3

Ayah tiri Jan dan para pembantu
Menunjuk

Adegan kan

menunjuk perilaku

kan kotor

kategori ayah tiri

hubungan Jan tidak

intim hanya

dilakukan

terhadap

pembantu

perempua

$n$ yang

masih

laJang,

tetapi juga

pembantu

wanita

yang telah

bersuami

atau

Janda.

Menunjuk

Adegan kan

menunjuk perilaku

kan kotor

kategori ayah tiri

ketelanJan Jan, tidak

gan hanya

terhadap

pembantu

perempua

n laJang

maupun tidak,

tetapi

kepada

Bibi Wad

yang

mengasuh

Jan. 


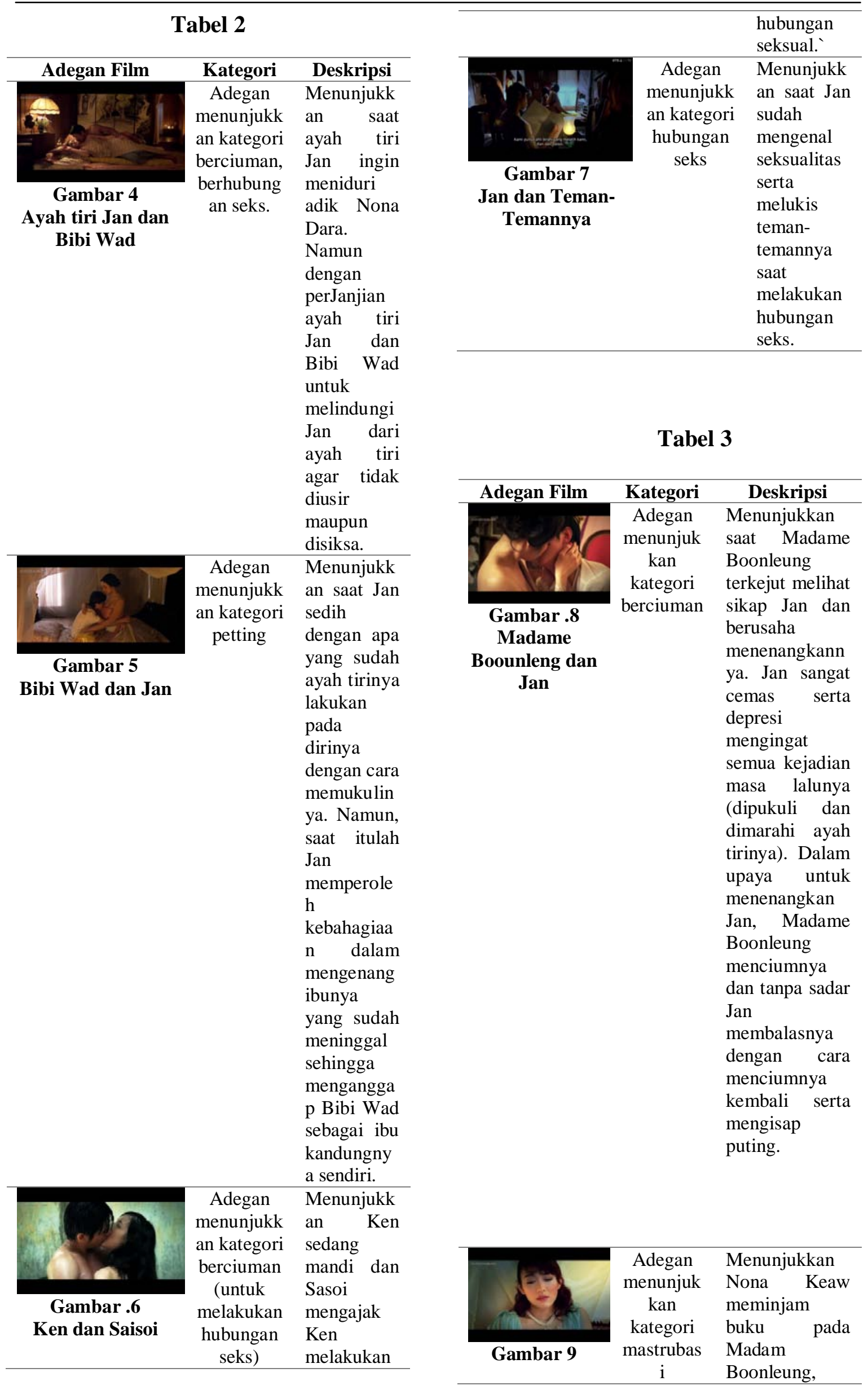




\begin{tabular}{|c|c|c|}
\hline Nona Keaw & & $\begin{array}{lr}\text { lalu } & \text { Nona } \\
\text { Keaw melihat } \\
\text { buku sketsa } \\
\text { hubungan seks. } \\
\text { Nona Keaw } \\
\text { tertarik } \quad \text { dan } \\
\text { mengambilnya. } \\
\text { Setelah itu } \\
\text { Nona Keaw } \\
\text { kembali } \\
\text { kamarnya, ke } \\
\text { melihat buku } \\
\text { tersebut dan } \\
\text { mengkhayalkan } \\
\text { nya. }\end{array}$ \\
\hline $\begin{array}{c}\text { Lambar } 10 \\
\text { Gan dan Keaw }\end{array}$ & $\begin{array}{c}\text { Adegan } \\
\text { menunjuk } \\
\text { kan } \\
\text { kategori } \\
\text { hubungan } \\
\text { intim } \\
\text { (kekerasa } \\
\text { n seksual) }\end{array}$ & $\begin{array}{l}\text { Menunjukkan } \\
\text { tindak } \\
\text { kekerasan } \\
\text { seksual yang } \\
\text { dilakukan Jan } \\
\text { terhadap Nona } \\
\text { Keaw. } \\
\text { Tindakan } \\
\text { tersebut } \\
\text { menunjukkan } \\
\text { sebagian upaya } \\
\text { pembalasan } \\
\text { dendam } \\
\text { terhadap Nona } \\
\text { Keaw. }\end{array}$ \\
\hline
\end{tabular}

Tabel 4

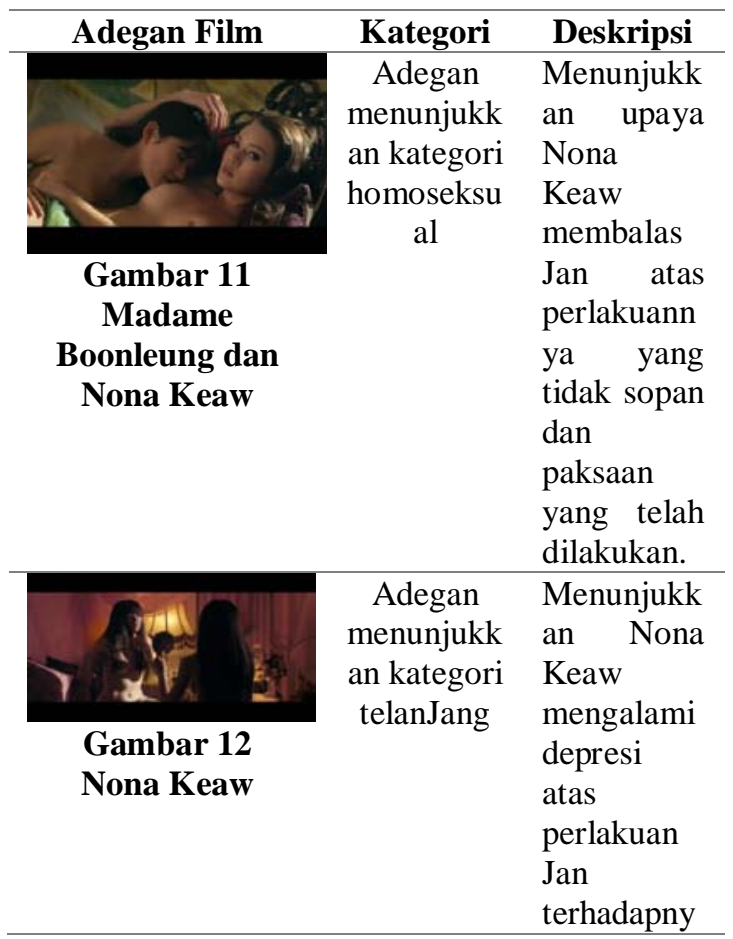

\section{B. Pembahasan}

Analisis naratif adalah analisis mengenai narasi baik narasi fiksi (novel, puisi, film, komik dan sebaginya) atau fakta (Eriyanto, 2013: 9). Berikut akan dipaparkan hasil analisis tentang narasi film dan kondisi kejiwaan setiap tokoh dalam film untuk meraih kepuasan.

- Alur cerita film Jan Dara

Film tersebut memiliki alur flashback, di mana Jan Dara saat berusia lanjut menceritakan kembali pengalamannya di masa kanak-kanak hingga dewasa. Alur cerita berbeda dengan versi asli dari novel dengan tujuan agar cerita lebih menarik. Alur cerita Jan Dara dalam film dibagi menjadi 2 bagian, yaitu Jan Dara The Beginning dan Jan Dara The Finale. Kedua cerita tersebut memiliki 
berkonsentrasi pada proses

perjalanan Jan Dara.

- Tema Film Jan Dara

Film Jan Dara merupakan film Thailand yang diproduksi selama 2 tahun. Film terbagi atas 2 bagian yaitu Jan Dara The Beginning yang diproduksi tahun 2012 dan Jan Dara The Finale diproduksi satu tahun setelahnya. Pada bagian pertama, film Jan Dara memiliki tema politik kekuasaan. Hal tersebut dapat diketahui dan dilihat dalam bentuk adegan di mana untuk dapat menguasai kekayaan beberapa tokoh mengambil jalan yang menurut mereka benar. Luang Wisnan, misalnya berupaya merebut kekuasaan dari pemilik rumah dengan menggunakan cara yang kotor yaitu seks, di mana dia menguasai setiap pembantu rumah tangga agar patuh terhadap dirinya dengan menundukkan mereka satu persatu melalui seks. Tokoh Jan juga melakukan hal sama dalam upaya merebut kembali haknya.

\section{- $\quad$ Setting Film Jan Dara}

Jan Dara mengambil setting paling banyak di rumah besar pijit Vanich, di mana Jan mengalami semua siksaan dan ketidakadilan. Selanjutnya terdapat rumah pengasingan di mana nenek Jan menyusun rencana membalas dendam.

- Tokoh

Tokoh dalam film Jan Dara memiliki sifat masing-masing yang dimainkan oleh pemain utama dan pemain pembantu, yakni: 


\begin{tabular}{cc}
\hline $\begin{array}{c}\text { Jan Dara (Mario } \\
\text { Maurer) }\end{array}$ & $\begin{array}{c}\text { Bibi Wad } \\
\text { (Bangkoj } \\
\text { Khongmalai) }\end{array}$ \\
\hline $\begin{array}{c}\text { Ayah tiri Jan/Luang } \\
\text { Wisnan (Sakrat }\end{array}$ & $\begin{array}{c}\text { Madame } \\
\text { Boonleung } \\
\text { (Rhatha } \\
\text { Ruekthamrong) }\end{array}$ \\
\hline Phongam) \\
\hline Nona Keaw (Sho \\
Nishino) \\
\hline Ken (Chaiyapol \\
Pupart) \\
\hline
\end{tabular}

\section{Posisi Perempuan dalam Film}

(Visual Pleasure and Narative

\section{Cinema)}

Visual pleasure and narative cinema merupakan karya Laura Mulvey (1975) di sebuah jurnal di Inggris. Artikel tersebut dianggap sebagai esai besar pertama yang menggeser observasi film terhadap teori psikoanalisis Sigmund Frued dan Jaques Lacan. Laura Mulvey menyatakan, film yang merupakan hasil bentukan sistem patriarki. Mulvey mengkritik, tokoh perempuan dalam film bukan sebagai pencipta makna, melainkan pembawa makna. Walaupun keberadaan perempuan dalam film bukan sebagai subjek, keberadaan perempuan dalam film tidak bisa dihapus atau dihilangkan. Hal tersebut berkaitan dengan sistem sosial patriarkal, di mana laki-laki mendominasi perempuan karena mereka adalah makhluk dikebiri. Hal tersebut juga menempatkan perempuan dalam posisi rendah, sehingga menjadi terbelenggu dalam sistem sosial patriarkal dan hanya menjadi objek fantasi dan obsesi lakilaki.

$$
\text { Mulvey menambahkan salah }
$$
satu teori Frued yakni scopophilia: kenikmatan yang diperoleh subjek saat menjadikan orang lain objek pandangan. Scopophilia dalam film merupakan bentuk kenikmatan yang diperoleh subjek (penonton) dengan memandang objek (perempuan) dalam film. Hal tersebut dapat terjadi karena penonton mengidentifikasikan diri mereka sebagai kamera, sehingga mereka dapat leluasa dan memiliki kendali penuh atas apa yang dilihat. 
Selain scopophilia, Mulvey juga

menambahkan tentang perilaku

penonton, yakni narcisstic dan

idenfication. Perilaku tersebut

merupakan bentuk perutamaan

penonton dan menganggap penonton

sebagai tokoh utama laki-laki dalam

film. Hal tersebut mengakibatkan

penonton dapat memuaskan ego

berkuasa dan memegang kendali atas

apa yang dilihat dan dilakukan pemeran

laki-laki.

Telah disebutkan sebelumnya, kehadiran perempuan dalam film bukanlah sebagai pencipta makana, melainkan pembawa makna. Perempuan dianggap makhluk yang terkebiri, di mana hal tersebut mengkaitkan posisi perempuan lebih rendah atau didominasi laki-laki dalam sistem patriarkal. Hal tersebut mengakibatkan perempuan dianggap sebagai objek pasif sedangkan laki-laki menjadi subjek aktif karena laki-laki memiliki kendali penuh atas apa yang dilihat.
Film Jan Dara merupakan film produksi Thailand yang memiliki unsur seksual dan erotis dalam beberapa scene (adegan). Film ini secara alur cerita merupakan kisah perjuangan anak muda pewaris sah dalam kondisi lingkungan tidak menguntungkan. Kondisi tersebut semakin parah karena rumah besar tempat tinggalnya dipenuhi nafsu bejat semenjak sang ayah tiri berkuasa. Film Jan Dara juga menampilkan adegan seksual yang dilakukan beberapa tokoh laki-laki dan perempuan tanpa sensor. Misalnya adegan ayah tiri Jan menggoda pembantu wanita untuk melakukan hubungan seksual da nada seorang pemuda mengintip perbuatan tersebut. 

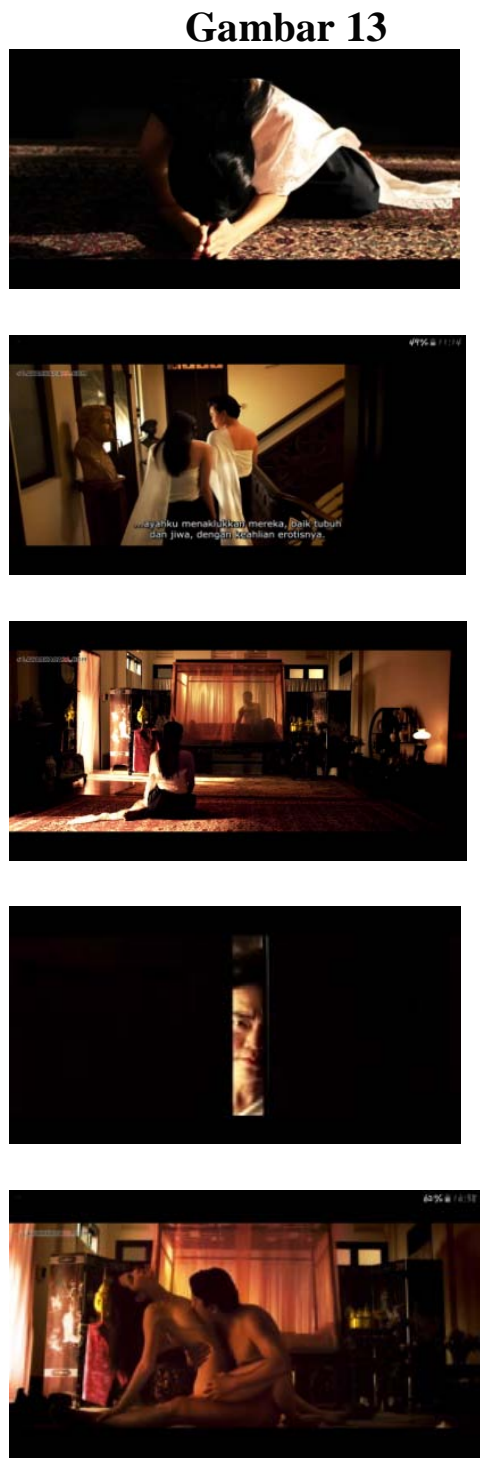

Gambar 13 menunjukkan adegan

di mana ayah tiri Jan Dara menghasut pembantu senior untuk mematuhi perintahnya membawakan pembantu perempuan untuk menjadi sasaran pemuas nafsunya. Pembantu senior kemudian membawakan pembantu perempuan, kemudian dia mengintip kegiatan tuannya. Berdasarkan gambar scene tersebut, produser ingin mengajak penonton merasakan kuasa tuan besar.

Hal tersebut dapat dilihat dari gambar di mana pembantu perempuan sedang besujud untuk memberi hormat. Posisi kamera memperlihatkan pembantu senior mengintip, kemudian berubah arah ke ayah tiri Jan Dara. Sekali lagi penonton diajak memuaskan ego dan fantasinya melalui adegan tersebut.

Selanjutnya terdapat adegan di mana penonton diarahkan untuk merasakan bagaimana rasanya menjadi tuan rumah yang berkuasa.
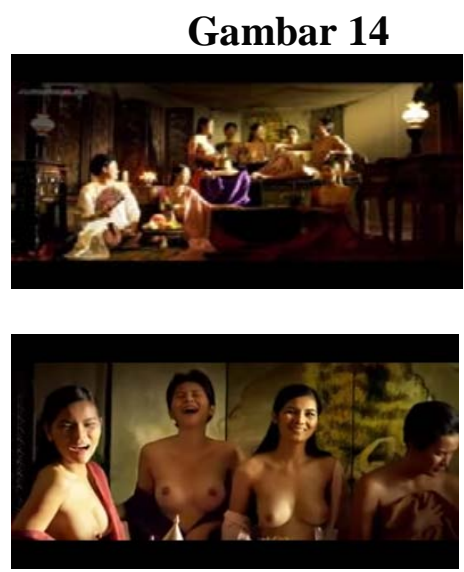

Gambar 14 menunjukkan adegan di mana sistem sosial patriarkal terdapat dalam film. Adegan tersebut memperlihatkan kondisi ayah tiri Jan 


bercengkerama dengan semua

pembantu perempuan. Kemudian

gambar di-close up ke arah pembantu

perempuan yang sedang tertawa dengan

kondisi setengah badan ke atas terbuka.

Kebahagiaan yang ditunjukkan nenek

Jan mengindikasikan bahwa mereka

(pembantu perempuan) merasa senang dengan perlakuan ayah tiri Jan. Adegan

tersebut menunjukkan, posisi

perempuan dalam film tersebut

merupakan pembawa pesan dan

kekuasaan atas rumah besar dipegang

ayah tiri Jan. Hal tersebut juga

mengindikasikan, semua pembantu

perempuan tunduk pada ayah tiri Jan,

sehingga nenek Jan memilih

meninggalkan rumah tersebut karena

sudah kehilangan kekuasaan.

Kompleks Oedipus merupakan

perkembangan psikoseksual anak yang

meniru perilaku orang tuanya terlebih

sang ayah. Ia jatuh cinta kepada ibunya

dan cemburu terhadap ayahnya. Seperti halnya tampak pada beberapa adegan

dalam film ini.

\section{Gambar 15}

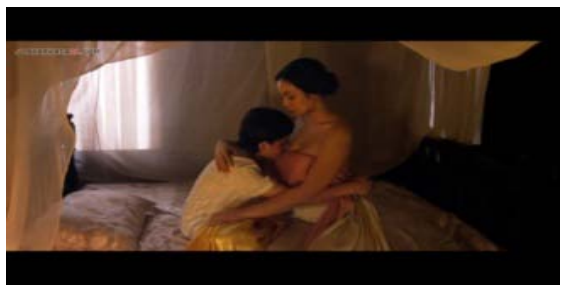

Gambar 15 menunjukkan ia tak pantas berperilaku seperti itu meskipun Bibi Wad mengizinkannya karena ingin Jan lebih tenang dan tidak menyalahkan diri sendiri akibat kematian ibu kandungnya.

\section{Gambar 16}

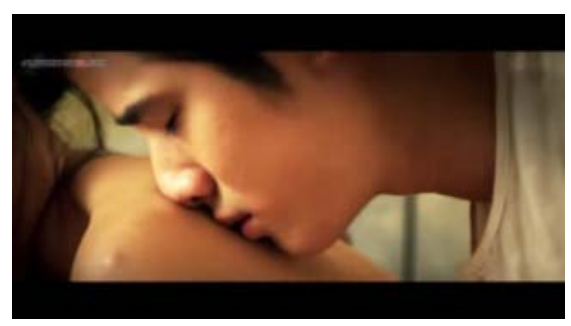

Gambar 16 menunjukkan Jan mencium Madame Boonleung, yang awalnya hanya meminta Jan menggosokkan es ke punggungnya. Madame Boongleung marah karena dia adalah istri kedua ayah tirinya. Sikap 
tersebut menunjukkan ketertarikan Jan

kepada Madame Boonleung.

\section{Gambar 17}
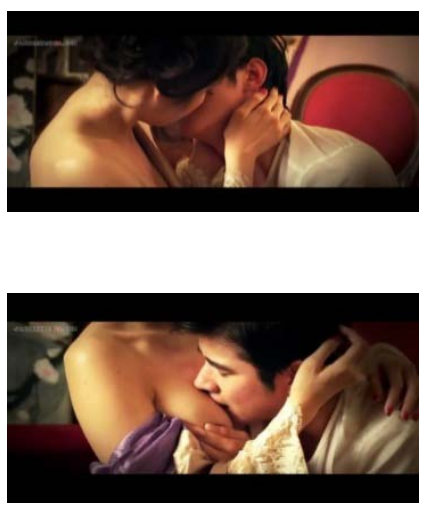

Gambar 17 menunjukkan Jan mencium puting payudara Madame Bounleung. Awalnya Boonleung hanya ingin menenangkan Jan, tetapi Madame Boounleung juga tertarik kepada Jan sehingga dia juga mencium Jan. Kemudian Jan sadar dan takut dihukum kembali seperti masa kecilnya sehingga ia lari ke rumah kecilnya.

\section{Gambar 18}

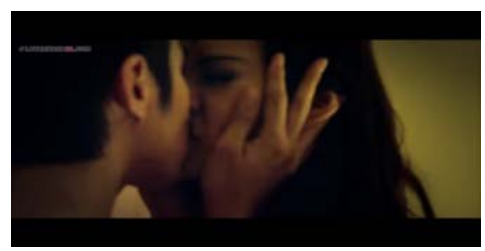

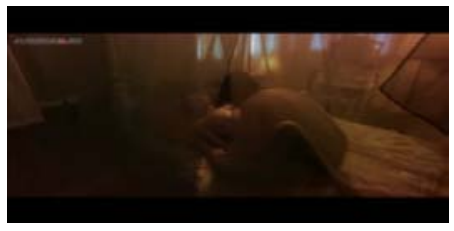

Gambar di atas menunjukkan Jan menginginkan Madame Boonleung karena ia ingat apa yang ayah tirinya lakukan pada masa kecilnya dan ingin membalas dendam dengan cara memaksa Madame Boounleung melayani nafsunya. Tetapi Madame Boounleung menolak. Jan menjawab, “Apakah kau ingat kaulah yang mengajariku karena aku ingat bau tubuhmu yang harum dan mengagumkan itu. Ayolah Jangan munafik...”

\section{Kajian Psikoanalisis Tokoh}

\section{- Jan Dara}

Jan Dara yang diperankan Mario Maurer memiliki sifat patuh terhadap orang yang lebih tua, 
rendah hati dan melindungi orang-orang yang ia sayangi.

Tetapi Jan berubah menjadi orang yang sama dengan ayah tirinya. Berdasarkan hal tersebut, menurut kajian psikoanalisis, tokoh Jan memiliki super ego yang dominan. Hal tersebut terlihat dari perilakunya. Jan mampu membedakan mana yang benar dan salah, serta mengikuti kebiasaan di rumah besar. Jan selalu memberi hormat pada ayah meski itu adalah sia-sia, karena ayahnya tidak peduli. Ketika Ken, teman sekaligus pelayannya, membujuknya berhubungan seks pada Saisoi, awalnya Jan menolak. Namun akhirnya bujukan Ken membuat Jan tak berkutik karena Jan juga memiliki ID yang mengontrol sifatnya. Kecemasan moralistik yang disebabkan super ego terbukti pada adegan saat Saisoi

diketahui hamil, dan muncul beberapa mekanisme pertahanan ego yakni:

a. Penyangkalan

Penyangkalan Jan ketika pelayan melaporkan pada Bibi Wad bahwa Saisoi hamil 3 bulan. Ken langsung menghitung berapa kali dia berhubungan seks dengan Saisoi. Namu n dugaan Ken benar, Saisoi tak dihamilinya. Ken melihat ekspresi ketakutan Jan. Jan menjawab, "Mati aku." Ken bisa membaca ekspresi ketakutan Jan serta berniat menggodanya. Jan mengajak ken keluar dari rumah besar. Namun Jan dan Ken mendengar teriakan Nona Kaew kepada Saisoi, "Pasti itu anak Ken, kan?” Ken 


\author{
menjawab bukan, dan \\ menunjuk Jan. Namun Jan \\ menjawab itu anak Ken. Jan \\ langsung \\ mempertanyakannnya kepada \\ Ken "Bagaimana bisa aku \\ yang menghamilinya, kan aku \\ hanya berhubungan seks satu \\ kali sedangkan kau sering \\ bercumbu dengannya.”
}

b. Peluapan

Pelupaan yang dilakukan Jan

saat dipukuli ayah tirinya

membuat orang-orang yang

sayang kepada dirinya

khawatir. $\mathrm{T}$ tak lama Bibi

Wad datang serta memanggil

Jan. Jan sadar dan bertanya

kepada Bibi Wad, “Apa benar

aku anak ayah.” Bibi Wad

menjawab, “Sudah cukup kau

menjadi anak ibumu dan

keponakanku.”

c. Proyeksi
Proyeksi yang dilakukan Jan

ketika ranjang kamar Ken

menjadi taman kenikmatan

untuk praktik erotis semua

pemuda di rumah besar.

Kegiatan melukis teman-

temannya yang sedang

berhubungan seks membuat

Jan melupakan duka dan

traumanya pada masa kecil.

d. Introjeksi

Introjeksi yang dilakukan Jan

ketika Bibi Wad berkunjung

ke rumah nenek untuk dipijit.

Nenek bisa menebak maksud

kedatangan Wad. Bibi Wad

bercerita bahwa Kaew hamil

anak Kajorn yang ternyata

kakak kandungnya sendiri, sedangkan Jan bukanlah anak

kandung dari Wisnan. Dia

datang atas permintaan

suaminya agar Jan bisa

menikah dengan Kaew untuk 
menutupi aib keluarga supaya

bisnis Wisnan tidak hancur.

Nenek memanfaatkan situasi

serta menerima tawaran

Wisnan untuk menikahi

Kaew agar bisa merebut harta

ibu kandungnya. Jan berhasil

mengembalikan kehormatan

keluarga ibunya serta

mengambil harta yang

diambil dari neneknya oleh

Wisnan. Tetapi masa lalu

selalu terbayang-bayang di

benak Jan, sehingga ingin

melakukan hal sama dengan

apa yang diperbuat ayahnya.

Jan mulai melaksanakan balas

dendam dengan cara meniduri

selirnya, yakni Madame

Boonleung dan menyiksa

perlahan-lahan batin maupun

fisik ayah tirinya.

- Luang Wisnan/Ayah Tiri Jan

Luang Wisnan yang diperankan

Sakrat Ruekthamrong memilik sifat dengki terhadap keluarga

Jan terutama Jan. Tetapi ayah tiri Jan --dalam Jan Dara The

Finale-- menyadari perilakunya

sangat salah. Namun

kesadarannya terlambat karena

Jan sudah membencinya.

Menurut kajian psikoanalisis,

tokoh Wisnan memiliki

dominasi ID dan ego besar. Hal

tersebut terlihat dari perilakunya

sehingga

menimbulkan

kecemasan realistik saat

mengetahui Nona Dara

mengandung anak orang lain

sebelum menikah. Hal tersebut

membuat Wisnan marah kepada

nenek Jan. Nenek memohon

Wisnan tidak meninggalkan

Dara serta menuruti

kemauannya. Wisnan meminta

harta nyonya besar berupa

rumah besar dan usaha di luar

negeri. Nenek setuju. Tetapi

kecemasan dalam pikirannya 
belum selesai karena muncul

kecemasan neurotik setelah

Nona Dara meninggal saat

melahirkan Jan sehingga

terdapat mekanisme pertahanan

yakni:

a. Penolakan

Penolakan ayah tiri Jan. Saat

Jan lahir, nyonya besar

bahagia tetapi Wisnan

membenci serta menganggap

Jan anak pembawa sial jarena

membuat ibu kandungnya

meninggal. Penolakan dan

kebencian yang ditunjukkan

pada Jan berlangsung hingga

Jan dewasa.

b. Pengalihan

Pengalihan Wisnan saat masa

berduka Nona Dara. Wisnan

mulai tertarik kepada Bibi

Wad karena cantik, ramah dan anggun. Wisnan ingin

memilikinya dan berniat

menjadikannya istri pengganti

Nona Dara.

c. Naluri Ego

Naluri ego Wisnan ketika nyonya besar menemui kerabatnya untuk dipijit, Wisnan memanfaatkan kepergiannya untuk memulai rencana jahatnya berhubungan seks dengan pelayan sekaligus Bibi Wad.

Rencana tersebut berhasil namun tidak bagi nyonya besar. Saat nyonya besar kembali dari pijit suasana berubah serta mengetahui bahwa Wad telah hamil dengan Wisnan. Nenek marah besar dan ingin membunuh Wisnan. Tetapi rencana nyonya besar gagal akibat melihat kelakuan asli Wisnan 
yang sedang pesta telanjang

dengan semua pembantu.

Nenek takut dan

meninggalkan rumah besar.

d. Melancholia

Saat Nona Dara meninggal, Wisnan terpukul dan berduka.

Nona Dara merupakan orang yang dia cintai meski Wisnan pernah dikecewakan oleh dirinya terkait kehamilannya.

e. Narcisme

Narcisme Wisnan terjadi ketika rencananya mengambil ahli harta nyonya besar berhasil. Wisnan percaya dirinya tidak bisa dikalahkan.

- Ken

Ken yang diperankan Chaiyapol Pupart memiliki sifat ceria, percaya diri, menghormati orang lebih tua, menghibur orangorang di sekitarnya, menjaga dan mendukung Jan saat senang maupun susah. Menurut kajjian psikoanalisis, tokoh ken memiliki dominasi ID besar. Hal tersebut terlihat dari perilakunya yang tak mampu membedakan mana yang benar dan salah. Namun perilaku Ken berubah di Jan Dara the Finale yang bisa membedakan mana yang benar dan salah, sehingga muncul beberapa mekanisme pertahanan ego yakni:

a. Narcisme

Saat ken bertarung dalam lomba yang diadakan Nona Kaew, tubuh yang indah serta wajah tampan mengundang ketertarikan hasrat seksual wanita. Ken adalah orang yang sangat percaya diri sehingga selalu memanfaatkan wajah serta tubuhnya untuk melakukan hubungan seks dengan 
banyak perempuan termasuk

Saisoi dan Nona Keaw.

Namun, Nona Keaw tak mau

karena dia adalah pelayannya.

Setiap kali Saisoi dan Ken

berhubungan seks, Nona

Keaw mengintipnya.

b. Eros

Saat Ken dan Jan berada di rumah nyonya besar. Jan mengajak Ken menemaninya beribadah di kuil. Tanpa sengaja Ken melihat perempuan cantik dan anggun. Dia jatuh cinta serta ingin menikahinya. Perempuan tersebut mengubah Ken menjadi lakilaki baik dan tak pernah melakukan hubungan seks dengan wanita manapun.

c. Naluri Ego
Naluri ego Ken terlihat ketika dia menikahi orang yang dia cintai serta mengubah gaya hidupnya. Ken bertanggung jawab dengan anak dan istrinya. Namun, Ken tidak lupa dengan tugasnya menjaga serta mendukung keputusan Jan. Suatu ketika Ken dan Jan kembali ke rumah besar. Ken melihat perilaku Jan berubah total persis perilaku Wisnan. Namun Ken tetap mendukungnya serta mengingatkan bahwa perbuatannya salah dan membuat orang-orang yang menyayanginya pergi. Jan marah dan menghina Ken.

\section{- Bibi Wad}

Bibi Wad yang diperankan Bangkoj Khumalai memiliki sifat penyayang, ramah, tidak 
sombong

dan

selalu

mengajarkan hal baik terutama

pada anaknya, Nona Kaew.

Menurut kajian psikoanalisis,

tokoh Bibi Wad dalam film

memiliki dominasi ego dan

super ego. Hal tersebut terlihat

dari perilakunya, di mana Bibi

Wad menjaga dan menyayangi

Jan dan selalu memberi tahu

mana yang salah dan benar

kepada Nona Kaew putrinya dan

Wisnan. Di dalam hidup Bibi

Wad muncul kecemasan realistik

saat Jan dilahirkan dan kematian

Nona Dara membuat Bibi Wad

khawatir akan perilaku Wisnan.

Bibi Wad belum tenang dan

mengakibatkan kecemasan

moralistik muncul, tetapi Bibi

Wad memanfaatkan situasi

ketika Wisnan tertarik pada

dirinya dan ingin berhubungan

seks dengannya. Sebelum

melakukan hubunngan seks, Bibi
Wad ingin Wisnan berjanji tidak

mengusir serta menyiksa Jan.

Meki rencana Wad berhasil

dalam melindungi Jan, tetapi ada

bebarapa mekanisme pertahanan

ego yang muncul di benak Wad,

yakni represi, pengalihan, dan

rasionaliasi di mana mekanisme

pertahanan ego ini ditunjukkan

untuk Nona Kaew dan Wisnan

agar tidak memusuhi Jan.

\section{- Nona Keaw}

Nona Kaew yang diperankan

Sho Nishino memiliki sifat sombong, tidak sopan terhadap ibunya sendiri, dengki terutama kepada Jan. Menurut kajian psikoanalisis, tokoh ini memiliki dominasi ID besar. Hal tersebut terlihat dari perilakunya yang mementingkan diri sendiri. Ketika masih kecil hingga dewasa dia selalu dimanja dan selalu diajarkan benci kepada Jan oleh ayah tirinya. 
Mekanisme pertahanan ego

Nona Kaew muncul agar dia menjadi orang paling penting bagi ayahnya, meskipun dia berpikir ibunya hanya memikirkan Jan. Mekanisme pertahanan ego berupa:

a. Penolakan

Penolakan dilakukan ketika Nona Kaew berhubungan seks dengan Ken, Jan memergokinya dan berpikir Ken tidak tahu malu. Jan tak terima dan memukuli Ken, sedangkan Nona Kaew berteriak minta tolong dengan alasan diperkosa. Tak lama Bibi Wad dan pelayan lainnya datang. Ken, Jan, dan Kaew dibawa ke rumah besar untuk bertemu Wisnan. Wisnan marah serta ingin melaporkan Ken ke polisi. Namun Jan sadar Ken tidak mungkin melakukannya karena Jan tahu Nona Kaew sangat licik. Jan membela dan mengakui dialah yang memperkosa Kaew bukan Ken.

b. Proyeksi dan Fantasi

Proyeksi dan fantasi dilakukan saat Nona Kaew meminjam buku pada Madame Boonleung. Tanpa sengaja buku sketsa Jan yang diambil Madame Boonleung ada di tumpukan buku-buku fashion. Buku sketsa tersebut berisi hubungan seks temanteman Jan. Nona Keaw tertarik dan mengambilnya tanpa diketahui Madame Boonleung. Mona Kaew melihat buku tersebut di kamarnya serta membayangkan dirinya berhubungan karena tidak 
bisa menahan hasrat

seksualitas.

- Madame Boonleung

Madame Boonleung yang

diperankan Rhathna Phongam

mempunyai sifat anggun, apa

adanya, penyayang, dan

memikirkan kebahagian

keluarganya. Menurut kajian

psikoanalisis, tokoh ini memiliki

ego dan super ego. Hal tersebut

terlihat dari perilaku yang

dilakukan. Madame Boonleung

mampu membedakan mana yang

benar dan salah. Namun perilaku

Madame Boonleung terhadap

Jan memang salah. Tetapi sifat

Madame Boonleung berubah

ketika melihat Jan berani kepada

ayah tirinya, sehingga Madame

Boonleung ingin melindungi

keluarganya terutama suaminya

(ayah tiri Jan) meskipun harus

melayani nafsu Jan Dara sehingga menimbulkan beberapa

kecemasan yakni:

a. Kecemasan Realistik

Saat Madame Boonleung

membantu Jan ketika

teraumanya di masa kanak-

kanak muncul kembali yang

menimbulkan ketakutan.

Madame

Boonleung

menenangkannya dengan cara

salah seperti mencium dan

memperbolehkan Jan

mencium putung

payudaranya.

b. Kecemasan Moral

Saat Madame Boonleung melihat sifat Jan berubah, sehingga membuat Madame Boonleung takut. Madame Boonleung bisa merasakan keadaan tidak beres terutama terhadap suaminya. Madame Boonleung menanyakan pada Jan atas perilakunya yang 
berubah cepat. Jan menjawab

tidak perlu tahu dan

menyatakan memikirkan bau

harum tubuh Madame

Boonleung. Hal itu membuat

Jan ingin berhubungan seks

dengan Madame Boonleung

untuk meraih kepuasan dan

membalas dendam terhadap

ayah tirinya.

\section{- Nyonya Besar/Nenek Jan}

Nyonya besar yang diperankan

Ratklao Amaradit memiliki sifat dermawan, rendah hati, tegas dan menjaga keluarganya dari masalah, meskipun gagal menjaga Jan dan Bibi Wad. Menurut kajian psikoanalisis, tokoh ini memiliki Id, Ego, Super Ego seimbang. Hal tersebut terlihat dari perilaku ketika mengambil keputusan serta menjaga Nona Dara yang hamil dan mendengar Bibi Wad hamil oleh Wisnan. Kecemasan

dalam diri nyonya besar muncul berupa:

1. Kecemasan Moralistic

Saat Nona Dara diculik Jom namun Jom meninggal saat kejadian. Kehamilan Nona Dara membuat nenek bingung mencarikan laki-laki untuk dijadikan suami. Tak lama nyonya besar menemukan laki-laki yang tepat untuk menikahi Dara yaitu Wisnan.

2. Kecemasan Realistik

Saat Nona Dara meninggal setelah melahirkan Jan. Nyonya besar merasakan ketakutannya pada Wisnan kaerna Wisnan akan membunuh Jan. nyonya besar melindungi Jan dengan cara dibawa ke rumah kecil.

3. Kecemasan Neurotic 
Saat harta dikuasai Wisnan.

Nyonya besar tak bisa berbuat

apa-apa untuk melindungi

Jan, karena Wisnan

menggunakan caranya sendiri

dalam melakukannya.

Nyonya besar lari dari

masalah tetapi tak bisa

melupakan peristiwa tersebut.

Mekanisme pertahanan

nyonya besar muncul sebagai

berikut:

a. Represi

Saat Nona Dara diperkosa

Jom dan temannya membuat

nyonya besar sedih.

Pemerkosaan tersebut

membuat Nona Dara hamil,

sehingga membuat nyonya

besar ingin melupakan

peristiwa tersebut dan

menikahkan Nona Dara

dengan Wisnan.

b. Pengalihan
Saat Nona Dara melahirkan

anaknya tapi kelahiran

membuat Nona Dara

meninggal. Nyonya besar

sedih akibat anak

kesayangannya meninggal.

Namun kesedihan itu tak

lama karena kehadiran bayi

mungil, yaitu Jan.

c. Regresi

Sifat asli Wisnan membuat nyonya besar menyesal memilih suami yang salah untuk anaknya dan membuat cucunya yaitu Jan mengalami nasib tragis. Awalnya dia menganggap Wisnan orang baik. Nyonya besar bertemu Wisnan di teater tempat Wisnan bekerja.

d. Format Aksi

Ketika nyonya besar mengetahui niat kedatangan

Bibi Wad yang membuat 


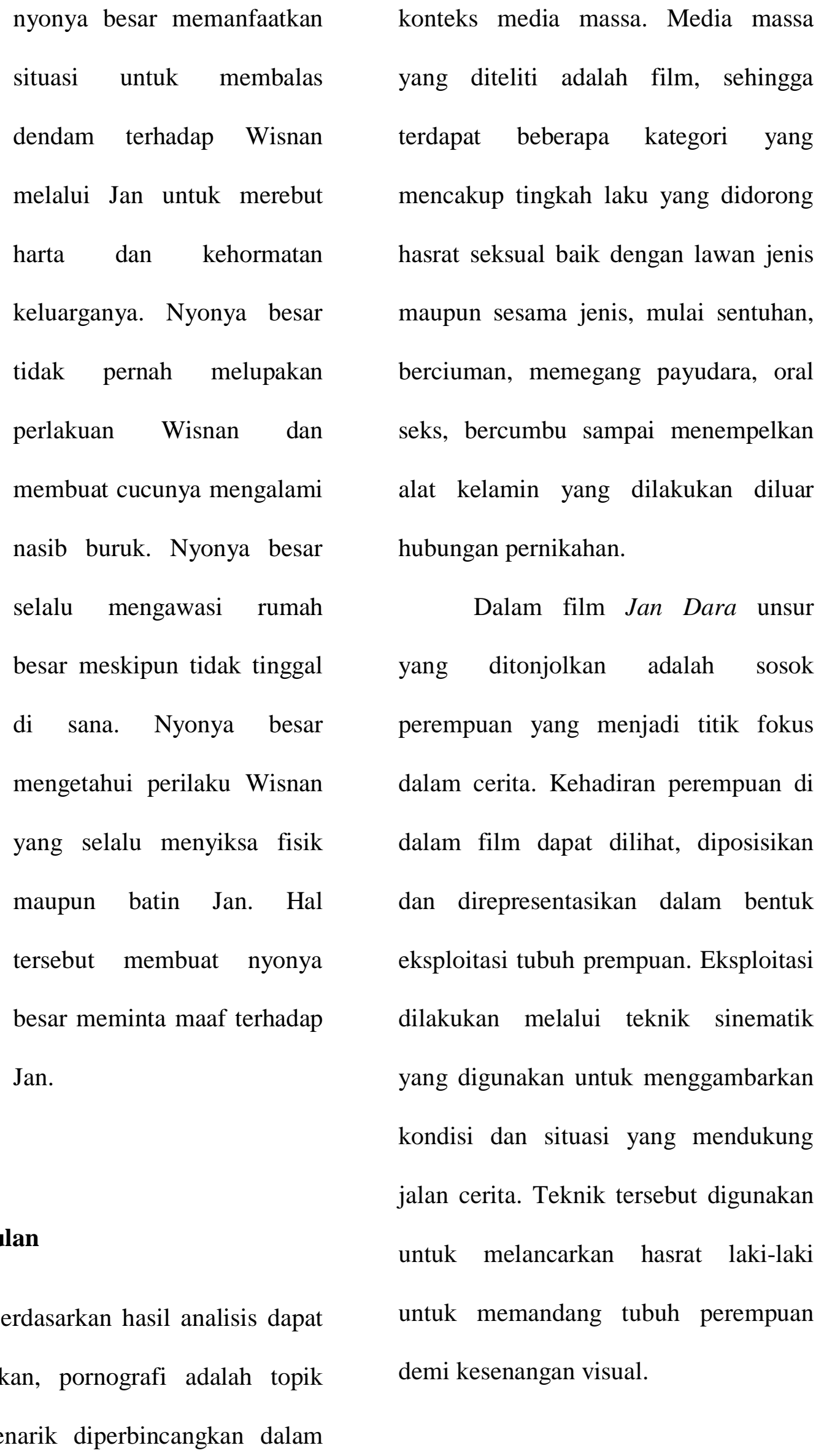

\section{Kesimpulan}

Berdasarkan hasil analisis dapa disimpulkan, pornografi adalah topik yang menarik diperbincangkan dalam 


Dalam film Jan Dara,

perempuan diposisikan sebagai objek

bagi pandangan laki-laki yang patuh

terhadap tatapan kamera (laki-laki).

Teknik sinematik tersebut

mengkonstruksikan perempuan sebagai

objek atau pembawa makna dan hasrat

pandangan laki-laki baik untuk orang-

orang di balik layar dan penonton.

Setiap tokoh dalam film memiliki sifat

dan penokohan berbeda-beda.

Perbedaan tersebut dimaksudkan untuk

memberikan variasi dalam cerita.

Dalam film ini setiap tokoh memiliki

cara beragam dalam meraih kepuasan.

\section{Referensi}

Bertens, K. (2016). Psikoanalisis Sigmund Freud. Jakarta: PT Gramedia Pustaka Utama.

Danesi, Marcel. (2010). Pengantar Memahami semiotika Media. Yogyakarta: Jalasutra.

Djubaedah, Neng. (2009). Pornografi Dan Pornoaksi Ditinjau dari Hukum Islam. Jakarta: Kencana Prenada Media.
Eriyanto. (2013). Analisis Naratif: Dasar-Dasar Dan Penerapannya Dalam Analisis Teks Berita Media. Jakarta: Kencana.

Januar, M. Iwan. (2014). Pornografi Bikin Ngeri. Bogor: Al-Azhar Press.

Javandalasta, Panca. (2011). 5 Mahir Bikin Film, Jakarta: Java Pustaka.

Khomsahrial, Romli. (2016). Komunikasi Massa. Jakarta: Grasindo.

Kustanto, Lilik. (2015). “Analisis Naratif:Kemiskinan Dalam Program Realitytv Pemberian Misterius di Stasiun SCTV." Jurnal Rekam Vol 11 (3).

Liliweri, Alo. (2011). Komunikasi Serba Ada Serba Makna. Jakarta:

Moleong, Lexy J. (2013). Metode Penelitian Kualitatkif. Bandung: PT Remaja Rosdakarya.

Panuju, Redi. (2017). Sistem Penyiaran Indonesia. Jakarta: Kencana Prenada Mediagroup.

Panuju, Redi. (2017). "Perilaku Mengakses Internet di Warung Kopi.” Jurnal Sosioteknologi Vol 16 (3): 259-270. DOI: http://dx.doi.org/10.5614\%2Fsost ek.itbj.2017.16.3.3

Pratista, H. (2008). Memahami Film. Yogyakarta: Homerian Pustaka

Rivi, Handayani. (2017). "Male Gaze dalam Fotografi Model : Objektifikasi dan Komersialisasi 
Tubuh Perempuan.” Jurnalisa Vol 3 (1).

Rumthe, D.B. dan Rio Leonard. (2017). "Makna Keluarga pada Kelompok Mafia: Analisis Semiotika Dalam
Film The Godfather-I.” Jurnal Kajian Media, Vol 1: 28-41.

Sunarto, Televisi, Kekerasan, dan Perempuan. Jakarta: Kompas Media Nusantara. 